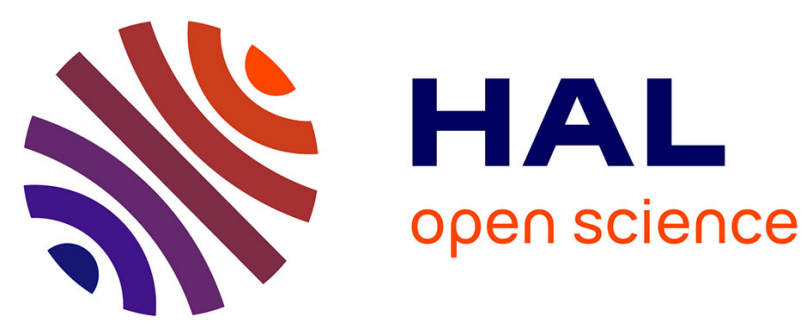

\title{
Equilibrium data and GC-PC SAFT predictions for furanic extraction
}

Eric Auger, Christophe Coquelet, Alain Valtz, Mqondisi Nala, Paramespri Naidoo, Deresh Ramjugernath

\section{- To cite this version:}

Eric Auger, Christophe Coquelet, Alain Valtz, Mqondisi Nala, Paramespri Naidoo, et al.. Equilibrium data and GC-PC SAFT predictions for furanic extraction. Fluid Phase Equilibria, 2016, 430, pp.57-66. 10.1016/j.fluid.2016.09.019 . hal-01371510

HAL Id: hal-01371510

https://hal-mines-paristech.archives-ouvertes.fr/hal-01371510

Submitted on 26 Sep 2016

HAL is a multi-disciplinary open access archive for the deposit and dissemination of scientific research documents, whether they are published or not. The documents may come from teaching and research institutions in France or abroad, or from public or private research centers.
L'archive ouverte pluridisciplinaire HAL, est destinée au dépôt et à la diffusion de documents scientifiques de niveau recherche, publiés ou non, émanant des établissements d'enseignement et de recherche français ou étrangers, des laboratoires publics ou privés. 


\title{
Equilibrium data and GC-PC SAFT predictions for furanic extraction
}

\author{
Eric Auger ${ }^{1}$, Christophe Coquelet ${ }^{1,2}$, Alain Valtz ${ }^{1}$, Mqondisi Nala $^{1,2}$, Paramespri. Naidoo ${ }^{2}$, \\ Deresh Ramjugernath ${ }^{2}$ \\ ${ }^{1}$ Mines ParisTech, PSL Research University, CTP - Centre of Thermodynamics of Processes, 35 Rue Saint Honoré, \\ 77305 Fontainebleau, France \\ 2 Thermodynamics Research Unit, School of Engineering, University of KwaZulu-Natal, King George V Avenue, \\ Durban 4041, South Africa
}

\begin{abstract}
The present study concerns phase equilibria measurements involving oxygenated components (furan and furfural) and potential solvents of extraction (n-hexane, ethanol and noctanol) using an ebulliometer at atmospheric pressure. New liquid-liquid equilibrium data concerning the ternary system furan + furfural $+n$-hexane are also presented. The experimental technique used for the liquid-liquid equilibrium measurements is based on the static analytic method. The two liquid phases are sampled using a syringe and analysed using gas chromatograph. Two thermodynamic approaches are considered for the data treatment: the first considers a dissymmetric approach using the NRTL activity coefficient model, and the second considers a group contribution model based on the PC-SAFT EoS (GC-PPC SAFT). The experimentally measured data were successfully correlated with the models proposed.
\end{abstract}

Keywords: furfural, furan, solvent, phase diagram, ebulliometer, equipment

*Corresponding author: Pr. Christophe Coquelet E-mail: christophe.coquelet@ mines-paristech.fr Tel: +33164694962 Fax: +33164694968 


\section{Introduction}

The development and improvement of second-generation biofuels and green chemistry relies on accurate phase equilibrium computations of molecules involved. Among these molecules, there is a specific growing interest on selective production of furfural from renewable biomass. Indeed, a number of chemical products and fuel (additives) can be produced from the starting material called furfural. Current uses of furfural include, mainly the production of furfuryl alcohol (resin production), linking foundry sand, and lubrication oil extraction. Moreover, acidic biomass hydrolysis and subsequent dehydration of the obtained C5 sugar xylose leads to furfural [1] and glucose into furans [2]. Therefore, extraction of furfural is a key point of the development of second generation biorefinery [3]-[7]. Finally, furan, which is industrially synthesized from furfural, is also used for the production of the solvent tetrahydrofuran, some polymers used as additives for detergents, and herbicides.

In biorefining, the determination of the process for separation or purification requires an accurate thermodynamic model. In the case of liquid-liquid extraction, information about the liquid-liquid equilibria (LLE) between solvent and solute permits the determination of selectivity between the solute and the solvent. Concerning the distillation processes, residue curves are used to determine the feasibility of the separation process. The residue curve is obtained by solving the Rayleigh distillation equation $\left(\frac{d x}{d t}=x-y, \mathrm{x}\right.$ and $\mathrm{y}$ are the compositions of liquid and vapour phases, respectively). Parameters of the thermodynamic models are determined from experimental data, but can also be determined from group contribution methods.

In this publication, we will present new sets of data: vapour-liquid equilibrium (VLE) data at atmospheric pressure for furan + ethanol, furan + n-octanol, and furan + furfural binary systems and LLE data at atmospheric pressure for the furfural $+n$-hexane binary system and furan + furfural $+n$-hexane ternary system. The authors have previously published VLE data concerning the furan $+n$-hexane binary system [8]. The models used in this work are the same as used in the previous paper [8].

A review of the literature shows that there are a few publications describing the modeling of binary mixtures similar in nature to those presented in this study with the GC-EoS with 
associating terms (Gonzalez Pietro et al., [9]). To the best of our knowledge there is no VLE data in the literature concerning the three binary systems or LLE data concerning the ternary system. The literature reveals that only Kolyuchkina et al. [10] has published two sets of LLE data concerning the furfural $+n$-hexane binary system. Moreover, it should be noted that literature contains some system measurements for components fairly similar to those measured in this study, for example, VLE data for 2,5 dimethyl furan + alcohols (ethanol, butanol, hexanol [11], [12]), 2-methylfuran + furfuryl alcohol, isopropyl alcohol + furfuryl alcohol, furan + furfural [13], and furan + n-hexane [8], [14]. There was also data in the literature for ternary systems such as alkanes + aromatics + furfural [15].

The new data are correlated using thermodynamic models, viz. the NRTL activity coefficient model [16]. The new data have also been used to extend the predictive thermodynamic model GC-PPC-SAFT. The extension of such models containing furfural and furan is challenging because of the polarity and the aromatic core of these molecules.

The first objective of this work is to present 3 new VLE, one LLE and one ternary data sets and their data treatments which are of high interest for design of separation units in biorefining. The second objective of this study is aimed to assess the predictive character of the thermodynamic model GC-PPC-SAFT.

\section{Experimental work}

\section{Materials}

Table 1 presents the characterisation of the chemicals used in this work. No further purification of the reagents was employed after gas chromatography analysis showed no significant impurities.

[Table 1]

\section{EXPERIMENTAL}

\section{Equipments}


All the experimental works were done at CTP laboratory.

\section{The vapour-liquid equilibrium apparatus and procedure}

The apparatus and experimental procedure are identical to the that presented in a previous publication (Nala et al. [8]). Briefly, the ebulliometer is an all-glass recirculating still equipped with a Cottrell pump. The still allows for the circulation of both liquid and vapour phases. The operating principle of the ebulliometer used is similar to the Othmer dynamic VLE still [17]. Sufficient heat was supplied to the reboiler contents to ensure continuous and smooth boiling and a high circulation rate (judged by counting the condensate drop rate). The equipment is used for atmospheric pressure measurements and therefore no pressure control system is included. Experimental uncertainties for temperature and equilibrium phase compositions are $\mathrm{u}(\mathrm{T}, \mathrm{k}=2)=0.01 \mathrm{~K}$ and $\mathrm{u}(\mathrm{z})=0.007$, respectively.

\section{The vapor-Liquid-Liquid equilibrium apparatus and procedure}

The newly designed VLLE cell is equipped with stainless steel end-caps which enclose the cell completely, preventing any loss of material. The new design comprises of three sampling points allowing sampling of liquid phase I, liquid phase II, and the vapour phase. The sampling points are equipped with air-tight rubber septa to prevent any loss of pressure within the cell. The temperature is measured using a type PT100 $\Omega$ platinum probe which is inserted through a port at the top of the stainless steel cap. The port is designed to fit the PT100 $\Omega$ with an adjustable bolt fitting which also eliminates the loss of pressure within the cell. The pressure inside the cell is regulated by the chemicals used. The glass used for this cell is capable of withstanding pressures of up to 4 bar. The pressure testing was undertaken by introducing nitrogen gas in the cell at room temperature. The recommended safe operating pressure is 3 bar, taking into account the effect of temperature on the glass. The capacity of the cell is up to $60 \mathrm{ml}$, which is adequate for continuous measurements and sampling without disturbance of equilibrium. A vacuum pump line is installed at the top of the cap. This is suitable during loading of the cell by inducing a small vacuum and allowing materials to flow into the cell. Air which may be present after loading of the cell is removed by inducing the vacuum. Figures 1 and 2 shows a mechanical drawing of the VLLE cell and the schematic diagram of VLLE apparatus setup used for measurements, respectively.

[Figure 1]

[Figure 2] 
The LLE cell used in this work was operated under atmospheric pressure, and thus only temperature was monitored. A standard probe Fluke-hart scientific 5628 was used for calibrating the platinum probe temperature sensor used in the LLE cell. The two probes were placed in an Ultra Kryomat ${ }^{\circledR}$ Lauda temperature controlled waterbath, which was allowed to reach stable thermal equilibrium. The accuracy of the equilibrium temperature is estimated to be $\pm 0.01 \mathrm{~K}$. The cell was dismantled and thoroughly cleaned with ethanol and allowed to dry in the fumehood for at least 1 hour. The cleaning procedure was employed prior to introducing a new system into the cell. The chemicals were introduced into the cell in adequate amounts such that a two phase mixture is formed and also to ensure that the interface is above the dense phase sampling point (i.e. the interface must be between the sampling points for the liquid phases). The cell was then immersed in the waterbath, the temperature set to a desired value and the magnetic stirrer switched on. The speed of stirrer motor had to be controlled during stirring to prevent emulsion of the liquid mixture. The two phase mixture was then stirred for at least 2 hours, thereafter the motor is switched off and the mixture was allowed to reach equilibrium. In 30-minute intervals, the liquid samples for each phase are withdrawn using a $5 \mu \mathrm{L}$ gas tight liquid syringe and injected into Perichrom Gas Chromatograph. GC detectors were calibrated by injection of known quantities of each chemical using a GC syringe. Equilibrium is deemed to have been achieved when the composition in each phase remains constant, at which time the mixture temperature is also recorded. For each system, a new value of temperature is set and procedure above repeated to get the next equilibrium point. Experimental uncertainties for temperature and composition are $\mathrm{u}(\mathrm{T}, \mathrm{k}=2)=0.01 \mathrm{~K}$ and $\mathrm{u}_{\max }(\mathrm{z})=0.007$, respectively.

\section{Systems studied and experimental data}

Each of the binary systems studied are representative of mixtures which play a role in biorefinery processes. They are listed in Table 2 All experiments were undertaken at atmospheric pressure (between 0.99 and 1.02 bar). LLE for the Furan + Furfural + n-hexane ternary system (was measured at $298.15 \mathrm{~K}$ and $323.15 \mathrm{~K}$. 
[Table 2]

\section{Models descriptions}

\section{Vapour-liquid equilibrium}

The $\gamma-\varphi$ approach involves the use of fugacity coefficient and activity coefficient to describe the non-idealities in liquid and vapor phases, respectively. The method is commonly used in the reduction of low pressure data. The criteria for phase equilibrium results in the equation for the combined method given by equation 1 .

$y_{i} \widehat{\varphi}_{i} P=x_{i} \gamma_{i} f_{i}$

$\mathrm{P}$ is the total pressure, $y_{i}$ is the mole fraction of component $i$ in the vapour and $\widehat{\varphi}_{i}$ denotes the fugacity coefficient used for describing non-idealities in the vapour phase, $x_{i}$ denotes the mole fraction of component $i$ in the liquid, and $\gamma_{i}$ is the activity coefficient describing nonidealities in the liquid phase. The fugacity of pure component at mixture $T$ and $P$ is given by equation 2.

$f_{i}=\varphi_{i}^{\text {sat }} P_{i}^{\text {sat }} \exp \left[\frac{V_{i}^{L}\left(P-P_{i}^{s a t}\right)}{R T}\right]$

In our case (atmospheric pressure) we have considered the vapour phase as an ideal gas and neglected the Poynting correction factor. Equation 3 presents the equilibrium condition.

$y_{i} P=x_{i} \gamma_{i} P_{i}^{s a t}$

The activity coefficient model used is NRTL (Renon and Prausnitz [16]) which is described by equation 4 .

$\ln \gamma_{i}=\frac{\sum_{i=1}^{c}\left(x_{j} \tau_{j i} G_{j i}\right)}{\sum_{k=1}^{c}\left(G_{k j} x_{k}\right)}+\sum_{j=1}^{c}\left[\frac{\left(x_{j} G_{i j}\right)}{\sum_{k=1}^{c}\left(G_{k j} x_{k}\right)}\left(\tau_{i j}-\frac{\sum_{k=1}^{c}\left(x_{k} \tau_{k j} G_{k j}\right)}{\sum_{k=1}^{c}\left(G_{k j} x_{k}\right)}\right)\right]$

Where $G_{j i}=\exp \left(-\alpha_{j i} \tau_{j i}\right) ; \tau_{i j}=\frac{\mathrm{g}_{i j}-\mathrm{g}_{j j}}{R T}$ and $\tau_{j i}=\frac{\mathrm{g}_{j i}-\mathrm{g}_{i i}}{R T} . \mathrm{g}_{i j}, \mathrm{~g}_{j i}, \mathrm{~g}_{i i}$ and $\mathrm{g}_{j j}$ are energies of interaction between the molecular pairs. It is important to note that $G_{j i} \neq G_{i j} ; G_{i i}=G_{j j}=$ $1 ; \tau_{i j} \neq \tau_{j i} ; \tau_{i i}=\tau_{j j}=0$. In our case, $\mathrm{g}_{i j}-\mathrm{g}_{j j}=C_{i j}+C_{i j} T(T-273.15)$.

The pure component vapour pressure is obtained from DIPPR correlation. The parameters used and the correlation is presented in appendix 1 . 


\section{Liquid-liquid equilibrium}

In order to correlate binary LLE data it is necessary to recall the criterion for phase equilibrium (equation 5).

$x_{i}^{\alpha} \gamma_{i}^{\alpha}=x_{i}^{\beta} \gamma_{i}^{\beta}$

The NRTL activity coefficient model is used to correlate the data.

\section{GC-PC SAFT EoS}

An alternative equation for describing liquid and vapour idealities can also be derived based on the phase equilibrium criterion. The same equation of state (equation 6) can be used for both liquid and vapour phases.

$$
\hat{f}_{i}^{\mathrm{V}}=y_{i} \hat{\varphi}_{i}^{V}=\hat{f}_{i}^{\mathrm{L}}=x_{i} \hat{\varphi}_{i}^{L}
$$

The modeling was performed by means of the PC-SAFT EoS. In this model, molecules are considered as chains of spherical segments, and the hard-chain fluid is taken as the reference system in the perturbation theory. The Helmholtz free energy is expressed as a sum of different contributions as:

$$
A=A^{0}+A^{h s}+A^{\text {disp }}+A^{\text {chain }}+A^{\text {asso }}+A^{\text {polar }}+\ldots
$$

where the first five terms relate to the non-polar interactions and follow the theory developed by Gross and Sadowski [18] $\left(\mathrm{A}^{0}\right.$ is the Helmholtz free energy of an ideal gas mixture, $\mathrm{A}^{\text {hs }}$ the contribution of the hard spherical segments, $A^{\text {chain }}$ the chain contribution, $A^{\text {disp }}$ the dispersion contribution interactions and $\mathrm{A}^{\text {asso }}$ the associating term due to $\mathrm{H}$-bonds). The last term $\mathrm{A}^{\text {polar }}$ takes into account the polar interactions and was computed by extending the theory of Gubbins and Twu [19-20] to chain molecules using a segment approach [21-22].

Each term in the SAFT EoS is characterized by one or several parameters. In order to make this model predictive, the parameters of a molecule can be determined from parameters of its different segments. The resulting EoS is called Group Contribution PC-SAFT [23-26]. Given that this article is concerned more with the presentation of experimental data and partly on thermodynamic modeling of molecules related to biomass treatment, the reader is invited to 
read relevant papers [23-26] in literature for a complete description of the GC-PPC-SAFT EoS and its parameterization. The group contribution method seems to be well adapted to these molecules which are numerous and varied.

The GC-PPC-SAFT EoS had already shown good description of vapor-liquid and liquidliquid equilibria for oxygenated and/or aromatic mixtures [8], [25]-[29]. This work intends to challenge this model with new experimental data for mixtures containing furan and/or furfural. Group parameters are reused from previous work.

\section{Furan}

With GC-PPC-SAFT, Nala et al. [8] modeled with a good accuracy VLE of furan + n-hexane and furan + toluene and this work therefore reuses the parameters (parameters of ethers for the oxygen atom of the furan and parameters of aromatics for the cyclic carbons).

The group decomposition of furan is as follows (see Tables 3 and 4 for the description of group parameters): $\mathrm{CH}$ aromatic: 4, -O- Furan: 1 and Aromatic cycle: 1 (to consider the nonnegligible influence of aromatic ring).

\section{Furfural}

The group segments of the furfural molecule refer to group segments of aldehydes and furans. For this reason, this work reuses these parameters. Nevertheless, the influence of the aromatic ring on the aldehyde branch is not negligible. Indeed, for furfural and benzaldehyde, quantum computing and measurements of Nuclear Magnetic Resonance (NMR) show that the branch close to the ring is perturbed by it. For this reason, polar moments of the furfural are reused from quantum computing (orbital description 6-31G* with the B3LYP of the Density Functional Theory). The global dipolar moment of the furfural computed by ab initio gives 3,6D. According to NMR, the dipolar moment present in the ring is reused from furan, and one of the aldehyde branch is adapted to reproduce the global moment computed by ab initio (Auger, [30]).

The group decomposition of furfural is as follows (see tables 3 and 4 for the description of group parameters): $\mathrm{CH}$ aromatic: 3, -O- Furfural: 1, $\mathrm{C}$ aromatic: 1, Aromatic cycle: 1 (to consider the non-negligible influence of aromatic ring).

For the alcohols, ethanol is composed of $1 \mathrm{CH}_{3}, 1 \mathrm{OH}$ and $1 \mathrm{CH}_{2}$ groups and for n-octanol: 1 $\mathrm{CH}_{3}, 1 \mathrm{OH}$ and $7 \mathrm{CH}_{2}$ groups. All the parameters are presented in Tables 3 and 4. 


\section{Cross association}

Although some experimental studies on associations of similar molecules show that mixtures of aromatic + alcohol should involve cross associations [31-35], this work neglects cross associations between furan and alcohols, here ethanol and n-octanol.

[Table 3]

[Table 4]

Commercial software Simulis ${ }^{\mathrm{TM}}$ from PROSIM, was used to correlate the experimental data with the NRTL model. An in-house software (Dr. Eric Auger) was used for the calculations with the GC-PPC-SAFT model. The model parameters are obtained by data regression using the least square optimization technique.

\section{Results}

Vapor-liquid equilibrium results

The results are presented in Tables 5 to 7 . Concerning the binary system furan + furfural, experimental problems were encountered in the analysis of the vapour phase and hence the objective function considered is based on TP Flash calculations. For the Furan-furfural binary system, the objective function is based on boiling temperature.

\section{Furan + furfural}

The data treatment using NRTL activity coefficient model is presented in Figure 3 and Table 5. Parameters are presented in Table 8. We can observe a good representation of the data (Table 9). Using the GC-PPC-SAFT, we have observed some problems in representing the data: this is mainly due to the fact that the boiling temperature of pure furfural is badly predicted.

\section{Furan + n-octanol}

The data treatment using the NRTL activity coefficient model is presented in Figure 4 and Table 6. Parameters are presented in Table 8. We observe a good representation of the data (Table 9). Using the GC-PPC-SAFT, we can see that the model can correctly predict the experimental data.

\section{Furan + ethanol}


The data treatment using the NRTL activity coefficient model is presented in Figure 5 and Table 7. Parameters are presented in Table 8. We can observe a good representation of the data by the two models (Table 9).

[Table 5]

[Figure 3]

[Table 6]

[Figure 4]

[Table 7]

[Figure 5]

[Table 8]

[Table 9]

\section{Liquid-liquid equilibrium results}

Table 10 presents the results for the furfural + n-hexane binary system. The GC PPC-SAFT was used to correlate the data. We can see in Figure 6 that this model doesn't predict very well the phase diagram. This is not a surprise: the parameters were predicted on VLE data and consequently, another parameter is required to predict LLE correctly. In effect, GC PPC SAFT parameters are originally adjusted on VLE data. To define new GC PPC SAFT parameters, we need LLE data of binary systems which include the groups used with the molecules studied in this work. However, from an industrial point of view, engineers prefer touse of the same set of parameters for VLE and LLE even if it causes a slight deterioration.

[Figure 6]

[Table 10]

The NRTL activity coefficient model is used to correlate the data. Table 11 presents the parameters obtained and the AAD. Figure 7 shows a comparison with the literature data from Kolyuchkin et al. [10].

[Table 11] 
In order to compare the results with literature data, we have used the Cox-Herington Plot for Coexistence Data. In effect, the equilibrium behaviour of LLE systems in the critical region has been widely investigated in literature. The understanding of LLE behaviour near the critical region for the furfural $+n$-hexane system was made possible by application of the Cox and Herington equation [36]. The Cox-Herington equation had been developed based on the Guggenheim equation [37] which is based on density of the two liquid phases and is given by equation 9 .

$\rho^{\alpha}-\rho^{\beta}=K\left(T_{c}-T\right)^{1 / 3}$

Where $K$ is the correlating parameter. Cox and Herington represented the temperature and composition relation in each phase for coexistence data with two correlating parameters (equations 10 and 11).

$$
\begin{aligned}
& \left(T_{c}-T\right)^{1 / 3}=A^{\alpha} \log \frac{x_{1}^{\alpha}}{1-x_{1}^{\alpha}}+B^{\alpha} x_{1}^{\alpha}<x_{1 c} \\
& \left(T_{c}-T\right)^{1 / 3}=A^{\beta} \log \frac{x_{1}^{\beta}}{1-x_{1}^{\beta}}+B^{\beta} x_{1}^{\alpha}>x_{1 c}
\end{aligned}
$$

$\alpha$ and $\beta$ represent the upper and lower liquid phases, respectively. $x$ is molar composition and the two constants A and B are two correlating parameters related by equation 12 .

$B=A \log \frac{1-x_{c}}{x_{c}}$

They showed that an expansion of logarithm near critical composition $x_{c}$ yields the following model equation for representation of equilibrium composition as function of temperature (equations 13 and 14).

$x^{\alpha}-x_{c}=K^{\alpha}\left(T_{c}-T\right)^{1 / 3}$

$x^{\beta}-x_{c}=K^{\beta}\left(T_{c}-T\right)^{1 / 3}$

The form of the equation is similar to that given by Guggenheim, but uses molar composition of the two immiscibly compounds instead of phase densities and is used to better correlate the coexistence curve in the critical region. The 1/3 factor in equations (Eqs. 13 and 14) justifies the linearity of the Cox-Herington plot and can be varied to obtain the best fit of data. A 
universal parameter $\sigma=0.325$ is normally used instead of $1 / 3$. The critical composition $x_{c}$ is also obtained by regression. The parameter obtained are presented in Table 12. In comparison with the modelling using NRTL activity coefficient model, we can conclude that Cox and Herington model leads to a better representation of the region close to the upper critical end point.

[Table 12]

[Figure 7]

Table 13 presents the results we have obtained for the ternary system. To test the consistency of the experimental data of the ternary system n-hexane (1) + Furan (2) + Furfural (3) the Othmer-Tobias correlation (equation 15, [38]) is used and plotted on the figure 8.

$$
\ln \left(\frac{1-x_{1}^{I}}{x_{1}^{I}}\right)=a+b \ln \left(\frac{1-x_{3}^{I I}}{x_{3}^{I I}}\right)
$$

Where $\mathrm{x}_{1}{ }^{\mathrm{I}}$ is the composition of the component 1 in the LI (n-hexane rich phase), $\mathrm{x}_{3}{ }^{\mathrm{II}}$ is the composition of component 3 in the LII (furfural rich phase), a and b are adjusted on experimental data.

In order to correlate the data, we have only considered the NRTL activity coefficient model. We have tried to use the NRTL parameters obtained using VLE data, but we fail to represent the data. Consequently, we have fitted new NRTL parameters. We have considered that the parameters between n-hexane -furan and furan - furfural were identical. We have fitted the NRTL's non randomness $\left(\alpha_{i j}\right)$ parameter but not considered any temperature dependency of the parameters. Table 14 and Figure 9 present the results.

[Table 13]

We can observe that the model represents very well the data (see Table 15 for the deviations).

[Table 14] 
[Table 15]

[Figure 8]

\section{Conclusions}

In this study, new VLE data at atmospheric pressure have been measured for three binary mixtures (Furan + Ethanol, Furan + Octanol and Furan + Furfural). Two new sets of data concerning liquid liquid equilibrium have been measured at atmospheric pressure for furfural + n-hexane binary system and the Furan + Furfural + n-hexane ternary system. These mixtures represent typical systems of biorefinery's processes. These new data, showing good consistencies, enable the extension of the GC-PPC-SAFT model to these interesting systems. Moreover, some improvements have to be done concerning the representation of the liquid liquid equilibrium. But the predictive skill of the model on these systems bodes well for the others molecules of interest in the field of the second generation biorefinery.

[Figure 9]

\section{Acknowledgements}

We are grateful to Jean-Philippe Passarello and Pascal Tobaly for their contribution to this work. Financial support from the ANR of France, through project Memobiol (ANR-09-CP2D10-04 MEMOBIOL), the National research foundation (NRF) and Sasol limited are gratefully acknowledged. 


\section{References}

[1] G. W. Huber, S. Iborra, A. Corma, Synthesis of transportation fuels from biomass: chemistry, catalysts, and engineering, Chem. Rev. 106 (9) (2006) 4044 - 4098

[2] Y. Yang, C. Hu, M. M. Abu-Omar, Conversion of glucose into furans in the presence of AlCl 3 in an ethanol-water solvent system, Bioresour. Technol. 116 (2012) 190 - 194

[3] T. Werpy, G. Petersen, A. Aden, J. Bozell, J. Holladay, J. White, A. Manheim, D. Eliot, L. Lasure, S. Jones, Top Value Added Chemicals From Biomass. Volume 1 - Results of Screening for Potential Candidates From Sugars and Synthesis Gas, 2004.

[4] H. E. Hoydonckx, W. M. Van Rhijn, Application of novel furan resins in composites, JEC Compos. 38 (2008) 34-35.

[5] W. De Jong, G. Marcotullio, Overview of biorefineries based on co-production of furfural, existing concepts and novel developments, Int. J. Chem. React. Eng. 8 (1) (2010)

[6] J. L. Cabezas, S. Beltrán, J. Coca, Isobaric vapor-liquid equilibrium data for furfural with chlorinated hydrocarbons, Fluid Phase Equilib. 62 (1-2) (1991) 163-172

[7] Y. Kar, H. Deveci, Importance of P-series fuels for flexible-fuel vehicles (FFVs) and alternative fuels, Energy Sources, Part A Recover. Util. Environ. Eff. 28 (10) (2006) 909-921

[8] M. Nala, E. Auger, I. Gedik, N. Ferrando, M. Dicko, P. Paricaud, F. Volle, J. P. Passarello, J.-C. de Hemptinne, P. Tobaly, P. Stringari, C. Coquelet, D. Ramjugernath, P. Naidoo, R. Lugo, Vapour-liquid equilibrium (VLE) for the systems furan+ n-hexane and furan+ toluene. Measurements, data treatment and modeling using molecular models, Fluid Phase Equilib. 337 (2013) 234-245

[9] M. González Prieto, F. A. Sánchez, S. Pereda J. Supercrit. Fluids 96 (2015) 53-67

[10] Kolyuchkina, G. Y.; Ponomarev, V. N.; Timofeev, V. S. Izv. Vyssh. Uchebn. Zaved., Khim. Khim. Tekhnol. 18 (1975) 1582-1585

[11] L. Kara Zaitri, L. Negadi, I. Mokbel, N. Msakni, J. Jose Fuel 95 (2012) 438-445

[12] A. Mejía, H. Segura, M. Cartes, J. A. P. Coutinho J. Chem. Eng. Data, 57 (10) (2012) 2681-2688

[13] W.-P. Tai, H.-Y. Lee, M.-J. Lee, Isothermal vapor-liquid equilibrium for binary mixtures containing furfural and its derivatives, Fluid Phase Equilib. 384 (2014) 134-142

[14] H. S. Wu, S. I. Sandler, Vapor-liquid equilibria of tetrahydrofuran systems, J. Chem. Eng. Data 33 (2) (1988) 157-162

[15] U. K. A. Kumar, R. Mohan, Liquid- Liquid Equilibria Measurement of Systems Involving Alkanes (Heptane and Dodecane), Aromatics (Benzene or Toluene), and Furfural, J. Chem. Eng. Data 56 (3) (2011) 485-490 
[16] H. Renon H., J.M. Prausnitz, Local compositions in thermodynamic excess functions for liquid mixtures, AIChE J. 14 (1968) 135-144

[17] D.F. Othmer, Composition of Vapors from Boiling Binary Solutions, Ind Eng. Chem. 20 (1928) 743-766.

[18] J. Gross, G. Sadowski, Perturbed-chain SAFT: An equation of state based on a perturbation theory for chain molecules, Ind. Eng. Chem. Res. 40 (4) (2001) 1244-1260

[19] K. E. Gubbins, C. H. Twu, Thermodynamics of polyatomic fluid mixtures-I theory, Chem. Eng. Sci. 33 (7) (1978) 863-878

[20] C. H. Twu, K. E. Gubbins, Thermodynamics of polyatomic fluid mixtures-II: Polar, quadrupolar and octopolar molecules, Chem. Eng. Sci. 33 (7) (1978) 879-887

[21] P. K. Jog, S. G. Sauer, J. Blaesing, W. G. Chapman, Application of dipolar chain theory to the phase behavior of polar fluids and mixtures, Ind. Eng. Chem. Res. 40 (21) (2001) 46414648

[22] P. K. Jog, W. G. Chapman, Application of Wertheim's thermodynamic perturbation theory to dipolar hard sphere chains, Mol. Phys. 97 (3) (1999) 307-319

[23] S. Tamouza, J.-P. Passarello, P. Tobaly, J.-C. de Hemptinne, Group contribution method with SAFT EOS applied to vapor liquid equilibria of various hydrocarbon series, Fluid Phase Equilib., 222-223 (2004) 67-76

[24] D. NguyenHuynh, J.-P. Passarello, P. Tobaly, J.-C. de Hemptinne, Application of GCSAFT EOS to polar systems using a segment approach, Fluid Phase Equilib. 264 (1-2) (2008) $62-75$

[25] D. NguyenHuynh, A. Falaix, J.-P. Passarello, P. Tobaly, J.-C. de Hemptinne, Predicting VLE of heavy esters and their mixtures using GC-SAFT, Fluid Phase Equilib. 264 (1-2) (2008) 184-200

[26] D. NguyenHuynh, J.-P. Passarello, J.-C. de Hemptinne, P. Tobaly, Extension of polar GC-SAFT to systems containing some oxygenated compounds: Application to ethers, aldehydes and ketones, Fluid Phase Equilib. 307 (2) (2011) 142-159

[27] A. Fredenslund, Vapor-Liquid Equilibria Using Unifac: A Group-Contribution Method Elsevier (2012)

[28] D. Nguyen-Huynh, J.-C. de Hemptinne, R. Lugo, J.-P. Passarello, P. Tobaly, Modeling liquid-liquid and liquid-vapor equilibria of binary systems containing water with an alkane, an aromatic hydrocarbon, an alcohol or a gas (methane, ethane, $\mathrm{CO} 2$ or $\mathrm{H} 2 \mathrm{~S}$ ), using group contribution polar perturbed-chain statistical associating fluid theory, Ind. Eng. Chem. Res. 50 (12) (2011) 7467-7483

[29] D. Nguyen-Huynh, J.-C. de Hemptinne, R. Lugo, J.-P. Passarello, P. Tobaly, Simultaneous liquid-liquid and vapour-liquid equilibria predictions of selected oxygenated 
aromatic molecules in mixtures with alkanes, alcohols, water, using the polar GC-PC-SAFT, Chem. Eng. Res. Des. 92 (12) (2014) 2912-2935

[30] E. Auger, "Equilibres de phases des fluides oxygénés issus du traitement thermochimique de la biomasse lignocellulosique," Univ. Paris XIII, 2012.

[31] S. H. Huang, M. Radosz, Equation of state for small, large, polydisperse, and associating molecules, Ind. Eng. Chem. Res.29 (11) (1990) 2284-2294

[32] E. M. Woolley, L. G. Hepler, Molecular association of hydrogen bonding solutes. Phenol in cyclohexane and benzene, J. Phys. Chem. 76 (21) (1972) 3058-3064

[33] E. M. Woolley, D. S. Rushforth, Molecular association of hydrogen bonding solutes, o-, m-, and p-cresol, in carbon tetrachloride, Can. J. Chem. 52 (4) (1974) 653-660

[34] S. Singh, C. N. R. Rao, Spectroscopic studies of self-association due to hydrogen bonding, J. Phys. Chem. 71 (4) (1967) 1074-1078

[35] R. B. Gupta, R. L. Brinkley, Hydrogen-bond cooperativity in 1-alkanol+ n-alkane binary mixtures, AIChE J. 44 (1) (1998) 207-213

[36] Cox. J.D., E. F. G. Herington, The coexistence curve in liquid-liquid binary systems, Trans. Faraday Soc. 52 (1956) 926-930

[37] E.A. Guggenheim, Variations on van der Waals' equation of state for high densities, Molecular Physics 9 (2) (1965) 199-200.

[38] D. Othmer, P. Tobias, Liquid-liquid extraction data-the line correlation, Ind. Eng. Chem. 34 (6) (1942) 693-696 


\section{Appendix}

Correlation from DIPPR 101 to calculate vapour pressure.

$$
P^{s a t}=e^{\left(A+\frac{B}{T}+C \ln (T)+D \cdot T^{E}\right)}
$$

with the following parameters (Table A).

Table A: Vapor pressure correlation parameters from Simulis ${ }^{\mathrm{TM}}$.

\begin{tabular}{ccccc}
\hline Parameters & Furan & Furfural & ethanol & n-octanol \\
\hline A & 74.738 & 94.57 & 73.304 & 144.11083 \\
B / K & -5417 & -8372.1 & -7122.3 & - \\
& & & & 13667.15667 \\
$\mathbf{C}$ & -8.0636 & -11.13 & -7.1424 & -16.82611 \\
D/ K & $7.4710^{-6}$ & $8.81510^{-3}$ & $2.885310^{-6}$ & $2.885310^{-6}$ \\
E & 2 & 1 & 2 & 6 \\
\hline
\end{tabular}




\section{List of Tables}

Table 1: Chemical characterisation

Table 2: Range of temperatures for the binary systems measured.

Table 3: Summary of the Group Contribution parameters used in this work with GC-PPCSAFT

Table 4: Quadrupolar parameters of Furan and Furfural with GC-PPC-SAFT

Table 5: Vapor-liquid equilibrium of the Furan (1) + furfural (2) binary system at atmospheric pressure. $\mathrm{u}(\mathrm{T}, \mathrm{k}=2)=0.01 \mathrm{~K}, \mathrm{u}(\mathrm{z})=0.007$.

Table 6: Vapor liquid equilibrium of the Furan (1) + n-octanol (2) binary system at atmospheric pressure. $\mathrm{u}(\mathrm{T}, \mathrm{k}=2)=0.01 \mathrm{~K}, \mathrm{u}(\mathrm{z})=0.007$.

Table 7: Vapor-liquid equilibrium of the Furan (1) + ethanol (2) binary system at atmospheric pressure. $\mathrm{u}(\mathrm{T}, \mathrm{k}=2)=0.01 \mathrm{~K}, \mathrm{u}(\mathrm{z})=0.007$.

Table 8: NRTL binary interaction parameters for the VLE systems

Table 9: Average Absolute Deviation on molar compositions and boiling temperatures

Table 10: Binary LLE data for the furfural (1) + n-hexane (2) system. $\mathrm{L}_{1}$ (furfural rich) and $\mathrm{L}_{2}$ (n-hexane rich) phases. $\mathrm{u}(\mathrm{T}, \mathrm{k}=2)=0.01 \mathrm{~K}, \mathrm{u}(\mathrm{x})=0.008$.

Table 11: NRTL binary interaction parameters for LLE system

Table 12 : Cox-Herington regression parameters for LLE system

Table 13: Ternary LLE data for n-hexane (1) + furan (2) + furfural (3) system at atmospheric pressure. $\mathrm{u}(\mathrm{T}, \mathrm{k}=2)=0.01 \mathrm{~K}$.

Table 14: Prediction of Ternary LLE data for n-hexane (1) + furan (2) + furfural (3) system at atmospheric pressure using NRTL activity coefficient model.

Table 15: NRTL binary interaction parameters for LLE system (n-hexane (1) - furan (2) and furan (2) - furfural (3))

\section{List of Figures}

Figure 1: Mechanical drawing of LLE cell 
Figure 2: Schematic diagram of VLLE apparatus setup used for measurements.

Figure 3: Vapor-Liquid Equilibrium diagram of the Furan (1) + Furfural (2) binary system at atmospheric pressure. Symbol: experimental data, solid line: NRTL model, dashed line: GCPPC-SAFT.

Figure 4: Vapor-Liquid Equilibrium diagram of the Furan (1) + n-octanol (2) binary system at atmospheric pressure. Symbol: experimental data, solid line: NRTL model, dashed line: GCPPC-SAFT EoS.

Figure 5: Vapor-Liquid Equilibrium diagram of the Furan (1) + ethanol (2) binary system at atmospheric pressure. Symbol: experimental data, solid line: NRTL model, dashed line: GCPPC-SAFT EoS.

Figure 6: Liquid - liquid equilibrium diagram of furfural $+n$-hexane binary system at atmospheric pressure. $(\Delta)$ : experimental data. Solid line: GC PPC-SAFT EoS prediction.

Figure 7: T-x diagram for furfural (1) + n-hexane (2) system at atmospheric pressure. ( $\square$ ) Kolyuchkina et al. [10], set 2, (ロ) Kolyuchkina et al. [10] set 1, $(\Delta)$ this work, solid line NRTL model, dashed line Cox and Herington data treatment, ( $)$ : UCEP.

Figure 8: Data treatment of the ternary Furan (1) + Furfural (2) +n-hexane (3) thanks to the Othmer-Tobias correlation (०): $298 \mathrm{~K}$, and (•): $323 \mathrm{~K}$

Figure 9: T-x diagram for n-hexane (1) + furan (2) + furfural (3) ternary system. $(\Delta)$ : data measured at $298.18 \mathrm{~K},(\square)$ : data measured at $322.96 \mathrm{~K}$. lines: NRTL activity coefficient model. 